\title{
Correction of atmospheric delay effects in radar interferometry using a nested mesoscale atmospheric model
}

Article

Accepted Version

Wadge, G., Zhu, M., Holley, R. J., James, L. N., Clark, P. A., Wang, C. and Woodage, M. J. (2010) Correction of atmospheric delay effects in radar interferometry using a nested mesoscale atmospheric model. Journal of Applied Geophysics, 72 (2). pp. 141-149. ISSN 0926-9851 doi: https://doi.org/10.1016/j.jappgeo.2010.08.005 Available at https://centaur.reading.ac.uk/30106/

It is advisable to refer to the publisher's version if you intend to cite from the work. See Guidance on citing.

To link to this article DOI: http://dx.doi.org/10.1016/j.jappgeo.2010.08.005

Publisher: Elsevier

All outputs in CentAUR are protected by Intellectual Property Rights law, including copyright law. Copyright and IPR is retained by the creators or other copyright holders. Terms and conditions for use of this material are defined in the End User Agreement. 


\section{CentAUR}

Central Archive at the University of Reading

Reading's research outputs online 


\section{Correction of atmospheric delay effects in radar interferometry using a nested mesoscale atmospheric model}

G.Wadge $^{1}$, M. Zhu ${ }^{1,2}$, R.J. Holley ${ }^{1}$, I.N. James ${ }^{3}$, P.A.Clark ${ }^{4}$, C. Wang ${ }^{3}$ and M.J.Woodage ${ }^{1}$

1. Environmental Systems Science Centre, University of Reading, Reading, UK

2. School of Earth, Atmospheric and Environmental Sciences, University of Manchester, Manchester, UK

3. Department of Meteorology, University of Reading, Reading, UK

4. Joint Centre for Mesoscale Meteorology, Met. Office, University of Reading, Reading, UK

Corresponding author:

G. Wadge Environmental Systems Science Centre, Harry Pitt Building, 3 Earley Gate, University of Reading, Reading RG6 6AL UK

(gw@mail.nerc-essc.ac.uk)

tel: (44) 1183786412

fax: (44) 1183786413 


\begin{abstract}
The temporal variability of the atmosphere through which radio waves pass in the technique of differential radar interferometry can seriously limit the accuracy with which the method can measure surface motion. A forward, nested mesoscale model of the atmosphere can be used to simulate the variable water content along the radar path and the resultant phase delays. Using this approach we demonstrate how to correct an interferogram of Mount Etna in Sicily associated with an eruption in 2004-5. The regional mesoscale model (Unified Model) used to simulate the atmosphere at higher resolutions consists of four nested domains increasing in resolution (12, 4, 1, $0.3 \mathrm{~km})$, sitting within the analysis version of a global numerical model that is used to initiate the simulation. Using the high resolution 3D model output we compute the surface pressure, temperature and the water vapour, liquid and solid water contents, enabling the dominant hydrostatic and wet delays to be calculated at specific times corresponding to the acquisition of the radar data. We can also simulate the second-order delay effects due to liquid water and ice.
\end{abstract}




\section{Introduction}

The use of satellite-borne Interferometric Synthetic Aperture Radar (InSAR) to measure ground surface motion is an established technique in space geodesy (Massonnet and Feigl, 1998), though it does not yet have an operational, dedicated satellite. It depends on the ability to measure unambiguous phase changes in the signals returned from the ground between two radar images of the same scene viewed from almost the same position in space (Rosen et al., 2000). Perfect knowledge of the satellites' positions and ground topography and atmospheric path, should enable the technique to measure a differential, line-of-sight (LOS) motion field to accuracies of a few millimetres. In practice, none of the above are perfectly known and the accuracy of the technique can be reduced by an order of magnitude or more as a result.

The variability of the atmospheric refractivity from the first time of image acquisition to the second in the interferometric pair of radar images is the most difficult source of error to remove (Goldstein, 1995). There are three main components that contribute to this variability; electron density in the ionosphere, air density in the neutral atmosphere and water content in the troposphere. The ionospheric variability outside of the polar regions, apart from localized "azimthual streaks" (Mattar and Gray, 2002), is usually of sufficiently long wavelength (hundred of kilometres) and amplitude to be treated as a simple planar gradient field at scales below $100 \mathrm{~km}$. The tropospheric water vapour field, however, is highly variable at length scales below $100 \mathrm{~km}$ and over time scales of one hour or less, and is also strongly modulated by the surface topography (Hanssen, 2001). This paper addresses the effect of this variability of the atmospheric refractivity at radio wavelengths and, in particular, how to correct for it in the context of differential InSAR applied to mountainous terrain.

A number of solutions have been proposed to mitigate these effects (see Ding et al., 2008 for a review) and they mainly fall into two groups: those that rely on a statistical treatment of the radar image data, coupled with assumptions of how the various error 
sources behave, and those that use independent measurements and models of the atmosphere at the time of radar acquisition. Statistical methods include stacking (Sandwell and Price, 1998), pair-wise logic (Massonnet and Feigl, 1998), the shortbaseline method (Berardino et al., 2002) and the permanent scatterers method (Ferretti et al., 2001). These methods are underpinned by the assumption that the ground motion signal is spatially stationary at the pixel level, whilst the atmospheric signal is not. Independent, calibratory methods have been devised that use continuous GPS estimates of delay (Li et al., 2006), satellite-borne radiometric measurements of water vapour content (Li et al., 2005) and forward atmospheric models of the water vapour field (Wadge et al., 2002, Webley et al., 2004). The forward atmospheric model approach has two big advantages: it does not require a large amount of compatible radar data to be available (as is the case with permanent scatterers), nor does it require other specific instruments to be working at the same time and place as the acquisition of the radar image (e.g. GPS). What it does require is access to one of the global numerical weather forecast analyses and a local, mesoscale adaptation of an atmospheric simulation code.

In this paper we describe the use of such a mesoscale forecast model, the Unified Model (UM), for calculating the atmospheric delay. Because the effects are especially pronounced over mountains and our motivation is to better measure the surface motion of volcanoes, we demonstrate its use on Mount Etna, Sicily, which rises $3.3 \mathrm{~km}$ above Sicily's east coast, bordering the Ionian Sea. The magnitude of the effect on InSAR results over Etna is well known (Tarayre and Massonnet, 1996; Delacourt et al., 1998 ; Beauducel et al., 2000). We have used this approach on data acquired by the ASAR radar on the Envisat satellite between 2004 and 2006. In section 2 we describe the UM model set-up for Etna, termed here the Etna-UM, and how it is initialised and run. Section 3 summarises the character of the 3D atmospheric flow and its water content over Etna. The ways in which different components of the atmosphere modulate the refractivity of radio waves and produce propagation delays within InSAR data are explored in section 4. In section 5 we demonstrate how the interferograms are corrected. 


\section{Atmospheric Forecast Models}

The practical use of forecast models of the atmosphere to correct for path delay effects experienced by InSAR was first demonstrated by Wadge et al. (2002) and Webley et al. (2004). They used a mesoscale, non-hydrostatic model code, NH3D, with a cell size of $1.7 \mathrm{~km}$ over the Etna region that was initialised using the most appropriate single radiosonde profile data or individual cell data from a global numerical weather prediction forecast model. From their results they recognised the need for a higher resolution model that was able to accept a more accurate initial field and that would represent the physics of atmospheric water better, in particular phase transitions and explicit convection. Such improvements have been implemented in the system described here, employing the U.K. Met Office's Unified Model (UM), and trials of this were reported by Holley et al. (2005) and Wadge et al. (2006). Puyssegur et al (2007) described the testing of the MM5 code in a similar way, at a resolution of $2 \mathrm{~km}$, over Lebanon and Foster et al (2006) used the same code at $3 \mathrm{~km}$ resolution over the volcanoes of Hawaii.

\subsection{The Unified Model}

We use the atmospheric module of version 5.5 of the UM code (Davies, 2005; Met Office, 2004). The UM is a non-hydrostatic, deep atmospheric, grid point model with an Arakawa-C grid in the horizontal plane and a terrain-following Charney-Philips grid in the vertical plane (typically 38 vertical levels). The main variables of interest extracted from the model are the three components of wind, potential temperature, Exner pressure, density and the contents of water vapour, liquid water and cloud ice.

\subsection{Nested Mesoscale Models of the Atmosphere}

The UM is run by the Met Office every six hours to produce numerical weather predictions at a global scale with a cell size of about $60 \mathrm{~km}$. Other meteorological organizations run their own forecast models, such as the European Centre for Medium Range Weather Forecasting (ECMWF). The analysis versions of global models are used 
to initialise our local models of the atmosphere over Etna (Etna-UM). An improvement in resolution is achieved in nested stages (Fig.1). Within the global model sits a $12 \mathrm{~km}$ resolution model domain with an area covering south central Europe and north Africa. Within this is a $4 \mathrm{~km}$ domain covering the central Mediterranean, then a $1 \mathrm{~km}$ domain with sea boundaries around Sicily, and finally a 300 m model domain over Mount Etna in northeast Sicily (Fig.2). Each model domain has a similar array size, for example the 300 $\mathrm{m}$ domain has about 300 by 300 cells. Increasing the spatial scale of the models in this gradual way allows the longer wavelength properties of the atmosphere in the surrounding region to be accommodated accurately. The orographic discontinuities at the domain boundaries are automatically blended to prevent any spurious vertical offsets due to different levels of height representation. We found that more than $99 \%$ of the water vapour content in each of our models occurred less than $6 \mathrm{~km}$ above the sea surface and below $9 \mathrm{~km}$ altitude above the summit of Etna. The time-stepping of the model calculations increases as the domain cell size decreases: from 5 minutes at $12 \mathrm{~km}$ resolution to 10 seconds at $300 \mathrm{~m}$ resolution. The model run time on 16 processors of a parallel supercomputer was about 1 hour for each domain. The equivalent time for a test run on a desktop workstation was about 24 hours.

\subsection{Initialisation and Parameterisation}

Two model initialisation schemes were tested; the ECMWF global atmospheric analysis $\left(0.5^{\circ}\right.$ latitude $\mathrm{x} 0.5^{\circ}$ longitude) data, and the equivalent $\mathrm{UM}$ analysis data produced by the Met Office. The ECMWF analysis seems to be superior to the equivalent global UM analysis in terms of the accuracy of the water vapour field around Sicily as measured against independent data. We suspect, but cannot prove, that this improvement is due to water vapour data over the Mediterranean from the Special Sensor Microwave/Imager (SSM/I) that are assimilated by the ECMWF analysis, but not by the UM analysis. Although the initial conditions are supplied by the ECMWF data, the nested models use the UM. The preferred starting times for each forecast model are 0600 UTC for descending passes of the Envisat satellite and 1800 UTC for ascending passes. The models are run for a 6-hour period, with output after each half-hour. The SAR data are 
acquired at 0911 UTC and 2046 UTC for the descending and ascending satellite passes respectively. The time step for the $300 \mathrm{~m}$ domain is $10 \mathrm{~s}$ and the lateral boundary conditions for the $300 \mathrm{~m}$ domain are interpolated from the $1 \mathrm{~km}$ domain every 15 minutes. Tests suggest this is adequate to capture the dynamics of the atmosphere even under conditions of high Froude number flow.

The physics represented by the Etna-UM includes land surface (vegetation-cover type, soil temperature and moisture) and planetary boundary layer processes, radiation, cloud microphysics and convection (Met Office, 2004). The orography at the $1 \mathrm{~km}$ scale uses the GLOBE (Global One-km Base Elevation) model, http://www.ngdc.noaa.gov/mgg/topo/globe.html. and the $300 \mathrm{~m}$ domain uses the Shuttle Radar Topography Mission (SRTM) 3-arc second elevation data The $1 \mathrm{~km}$ and $300 \mathrm{~m}$ domain land use data are from International Geosphere Biosphere Programme (IGBP) $1 \mathrm{~km}$ dataset http://edcsns 17.cr.usgs.gov/glcc/. Soil moisture data are derived from climatological values and therefore the model is not sensitive to recent rainfall events.

\section{Nature of the Model Water Fields}

The character of individual forward atmospheric models over Mount Etna has been discussed by Wadge et al. (2002), Webley et al. (2004) and Favalli et al. (2004). At relative low wind speeds and Froude numbers the atmosphere splits around the volcano, whilst it can also move over the volcano's summit at higher Froude number flow. Vortex development and shedding is seen in the mountain's lee together with complex downward intrusion of low water vapour masses from higher altitudes. The regional flow

of the troposphere over Etna is from west to east and so the eastern, lee, slopes tend to have more complex patterns of water vapour variability and convective cloud formation than those to the west. This is compounded by the land-sea breeze effect across the eastern shore of Etna with the Ionian Sea (Zhu et al., 2008). 
More generally, it is insightful to consider the water vapour field over mountains such as Etna as having two components. The first is a vertically varying, horizontally constant component that is intersected by the orography. The content of water vapour in this component declines approximately exponentially with altitude (Foster and Bevis, 2003). The second is a more dynamic, horizontally perturbed component caused partly by the motion of synoptic systems with horizontal gradients and partly by the turbulent interaction between the wind and the orography. It is possible to separate these two components using knowledge of the orography. This isolates the relative contribution of the horizontally perturbed component, which cannot be adequately represented without an atmospheric modelling approach. Zhu et al. (2008) used a functional fit to the variation of water vapour data with altitude for both a MODIS water vapour field and the corresponding Etna-UM model field, separating the mean horizontal component from the total field to leave the horizontally perturbed component. Fig. 3 shows both components decomposed in this way, for the observed and model data. Power spectral analysis shows that the horizontally perturbed component has a spectral structure with a slope of $-5 / 3$, similar to GPS-derived results (Williams et al., 1998), whilst the equivalent slope for the horizontal mean component on Etna is about -3 and is determined by the orography (Zhu et al., 2008).

The ability of the UM to represent these two components of the water vapour field largely determines how successful this technique is in correcting for the delay. The mean horizontal component should be relatively easy to simulate provided that the initial conditions at the global scale are accurate. The horizontally perturbed component is more difficult to simulate because it depends on factors such as the local soil moisture and the generation of small convection cells.

\section{Radio Wave Delay}

The refractivity of the atmosphere through which a radar wave travels imparts a phase delay (or advance), which can vary in both space and time due to the dependence of 
refractivity on various atmospheric properties. A general equation for the refractivity, N, of the atmosphere can be written (Hanssen, 2001):

$\mathrm{N}=\mathrm{k}_{1} \mathrm{P} / \mathrm{T}+\left(\mathrm{k}_{2} \mathrm{e} / \mathrm{T}+\mathrm{k}_{3} \mathrm{e} / \mathrm{T}^{2}\right)+\mathrm{k}_{4} \mathrm{n}_{\mathrm{e}} / \mathrm{f}^{2}+\mathrm{k}_{5} \mathrm{M}_{1}$

where $\mathrm{k}_{1}=77.6 \mathrm{~K} \mathrm{kPa}^{-1}, \mathrm{P}$ is the total atmospheric pressure in $\mathrm{hPa}, \mathrm{T}$ is the absolute temperature in Kelvin, $\mathrm{k}_{2}=23.3 \mathrm{~K} \mathrm{hPa}^{-1}, \mathrm{k}_{3}=3.75 \times 10^{5} \mathrm{~K}^{2} \mathrm{hPa}^{-1}$, e is the partial pressure of water vapour in $\mathrm{hPa}, \mathrm{k}_{4}=-4.028 \times 10^{7}, \mathrm{n}_{\mathrm{e}}$ is the electron density per cubic metre, $\mathrm{f}$ is the radar frequency (5.3 Ghz for the ENVISAT data used here), $\mathrm{k}_{5}=1.45$ and $\mathrm{M}_{1}$ is the liquid water content.

The first term on the right-hand side of equation 1 is the so-called hydrostatic term (Davis et al., 1985) that quantifies the effect of the induced dipole moment of the non-water vapour constituents of the air. The second term is the so-called wet term that quantifies the effects of both the induced and the permanent dipole moments of the water vapour molecules. The third term represents changes of refractivity in the ionosphere and the fourth term is that due to the effects of liquid water in the atmosphere. In addition there is the potential for other, mostly minor, delays from hail, snow, aerosols and volcanic ash (Solheim et al., 1999).

The two-way radar phase delay, $\delta$, in metres can be calculated from the refractivity variation along the radar LOS between the local ground elevation and the altitude of the top of the atmosphere by:

$$
\delta=\left(2 \times 10^{-6}\right) / \cos \theta \int \mathrm{N}(\mathrm{z}) \mathrm{dz}
$$

where $\theta$ is the radar slant angle (from zenith, between $19^{\circ}$ and $25^{\circ}$ for ASAR IS2 image mode data) and $\mathrm{z}$ is the altitude. We now show how each of the individual terms of equation (1) are calculated in terms of radar phase delay. 


\subsection{Hydrostatic Delay}

The hydrostatic term of equation 1 can also be represented as an expression relating the zenith (vertical) hydrostatic delay (ZHD) in $\mathrm{mm}$ to the surface pressure $\left(\mathrm{P}_{\mathrm{s}}\right)$ in millibars by:

$$
\mathrm{ZHD}=(2.2779 \pm 0.0024) \mathrm{P}_{\mathrm{s}} / f(\lambda, \mathrm{H})
$$

where, $\quad f(\lambda, \mathrm{H})=(1-0.00266 \cos 2 \lambda-0.00028 \mathrm{H})$,

$\lambda$ is the latitude, and $\mathrm{H}$ is the surface height in $\mathrm{km}$ above the ellipsoid (Elgered et al., 1991). The magnitude of the ZHD is about $2.3 \mathrm{~m}$.. However, the temporal variability, which is what impacts differential InSAR, varies by a small proportion of the total delay and slowly, over long spatial wavelengths. The effect is modulated by the topography, which has a vertical range of $3.3 \mathrm{~km}$ over Etna. The value of $\mathrm{P}_{\mathrm{s}}$ can be measured on the

ground in a few places and interpolated over the whole area. A much more accurate mapping of $\mathrm{P}_{\mathrm{s}}$ is produced directly by the Etna-UM.

\subsection{Wet Delay}

The wet delay requires knowledge of the precipitable water vapour content (PWV) integrated along the radar path. Askne and Nordius (1987) showed that the quotient (Q) of the zenith wet delay (ZWD) to the integrated PWV:

$$
\mathrm{ZWD} / \mathrm{PWV}=\mathrm{Q}
$$

is given by:

$$
\mathrm{Q}=10^{-8} \rho \mathrm{R}_{\mathrm{v}}\left[\left(\mathrm{k}_{3} / \mathrm{T}_{\mathrm{m}}\right)+\mathrm{k}_{2}\right]
$$


where $\rho$ is the density of liquid water, $R_{v}$ is the specific gas constant of water vapour, equal to $461.524 \mathrm{~J} \mathrm{~kg}^{-1}$, and $\mathrm{T}_{\mathrm{m}}$ is the mean atmospheric temperature defined by

$$
\mathrm{T}_{\mathrm{m}}=\left(\int \rho_{\mathrm{v}} \mathrm{dz}\right) /\left(\int \rho_{\mathrm{v}} / \mathrm{T} \mathrm{dz}\right)
$$

where $\rho_{v}$ is the density of water vapour, $\mathrm{T}$ is the temperature and $\mathrm{z}$ is the altitude within the atmosphere.

Knowledge of $\mathrm{T}_{\mathrm{m}}$ usually comes from empirical, climatically-derived relationships (Emardson and Derks, 2000). Values of Q derived in this way vary between about 6.0 and 7.0 and Webley et al. (2004) used a constant value of 6.3 to compute the delays from model-derived integrated PWV values over Etna. However, using the output of the EtnaUM models, $T_{m}$ can be calculated explicitly along the radar paths taking the orographic height into account. Such values of Q for the radar LOS are shown in Fig. 4 for a typical set of model outputs over Etna at different times of year. There is an obvious increase in values as the elevation of the surface increases, due to the decreasing average temperature along the LOS. There is also a clear seasonal effect, with higher summer temperatures resulting in lower values. The data show that using model-derived values for $\mathrm{Q}$ gives results that are typically more accurate by several percent relative to those using a constant value, and in extreme cases by up to fifteen percent.

\subsection{Ionospheric Delay}

Localised ionospheric disturbances producing phase offsets, often advances, several hundred kilometres long and a few kilometres wide are known from polar regions and sometimes elsewhere (Mattar and Gray, 2002). However, for the Etna region the ionospheric variability in refractivity is generally smoothly varying at the hundredkilometre scale and independent of the underlying topography (Hanssen, 2001). Hanssen (2001) showed that for a C-band radar such as Envisat, with an appropriate mapping function, the delay or advance of phase $(\delta)$ in metres during radar propagation through the ionosphere is given by: 
where a TECU (Total Electron Content Unit) is equivalent to $10^{16}$ electrons $/ \mathrm{m}^{2}$. That is, there will be a delay of $15 \mathrm{~mm}$ for a change of one TECU along the path. We have estimated the local gradients of electron content above Etna at the time of our radar acquisitions from European-wide mapping (ionosphere.rcru.rl.ac.uk). These data show that for the descending passes (0915 UTC) the gradients are typically to the southeast, and to the southwest for the ascending passes (2046 UTC). Absolute values and gradients were quite low during the period of our study (2004-2006), close to the solar minimum. Using equation 6 , average delay gradients of $1.2 \mathrm{~mm} / 100 \mathrm{~km}$ for ascending passes and $2.2 \mathrm{~mm} / 100 \mathrm{~km}$ for descending passes can be calculated, with peaks of 3 and $6 \mathrm{~mm} / 100$ $\mathrm{km}$ respectively. The delays manifest in the interferograms will be the gradient differences between the two days. Because many of the gradients have the same orientation and sign, most of the differences will be even smaller than the values for single scenes, though a few will be larger. Overall these long-wavelength phase gradients due to the ionosphere in the Etna interferograms are one to two orders of magnitude smaller than the wet delay effect.

\subsection{Liquid Water and Ice Delay}

The fourth term of equation 1 relates the refractivity to the liquid water content of the atmosphere. For the small particles of suspended liquid water present in clouds, the signal delay can be approximated from the refractivity, $\mathrm{N}_{1}$, using the Clausius-Mossotti equation:

$$
\mathrm{N}_{1}=1.5 \mathrm{M}_{1} / \rho_{1}[(\varepsilon-1) /(\varepsilon+2)]=1.45 \mathrm{M}_{1}
$$

where $M_{1}$ is the mass of liquid water particles per unit volume, $\rho_{1}$ is the density of water, $\varepsilon$ is the permittivity of water and $\mathrm{M}_{1} / \rho_{1}$ is the mass fraction of the suspended particles (Solheim et al., 1999). Although the permittivity of water is a weak function of 
temperature (ranging from around 92 to 74, Solheim et al., 1999), the refractivity is approximately proportional to the total liquid content along the LOS. As Hanssen shows (Table 6.1, 2001) the typical liquid water contents of clouds can yield LOS delays ranging from $0.1 \mathrm{~mm} / \mathrm{km}$ in stratiform clouds to about $3 \mathrm{~mm} / \mathrm{km}$ in cumulo congestus and cumulo nimbus clouds. Ice clouds have even smaller delay effects $(<0.1 \mathrm{~mm} / \mathrm{km})$. However for droplets bigger than $\sim 1 \mathrm{~mm}$ (for example rain and hail) forward scattering processes are the dominant contribution to phase shifts, and the delay calculation would require a more involved calculation of scattering characteristics. From the 3D fields produced by the Etna-UM the integrated path values of $\mathrm{M}_{1}$ are extracted for each radar LOS separately for liquid and solid water components.

\section{Delay Correction}

Fig.5 shows the general scheme for correcting interferograms for atmospheric delays using the Etna-UM. The interferograms are constructed from pairs of synthetic aperture radar (SAR) images acquired by the ASAR radar aboard the Envisat satellite. Two sets of images were acquired between late 2004 and 2006, one from the satellite in ascending mode (south to north) looking to the east, and one from the descending mode (north to south) looking to the west (Fig.2). Each interferogram was processed using precise orbit information to minimise baseline errors, and the direct effect of topographic modulation of the phase returned from the ground surface was corrected using a $10 \mathrm{~m}$ horizontal resolution digital elevation model.

For each daytime, descending-pass radar acquisition, a corresponding water vapour image from the Medium Resolution Imaging Spectrometer (MERIS) radiometer onboard Envisat was also acquired, where possible. Following masking of cloud-covered areas, such MERIS water vapour images gave a vertically integrated water vapour content image at a horizontal resolution of about $300 \mathrm{~m}$ over the Etna area. After scaling, this was compared directly to the equivalent result derived from the 3D water vapour field and used to validate the performance of the Etna-UM. Mis-matches between the two in the 
range of 1-2 mm PWV over Etna were demonstrated by Zhu et al. (2007). Note that for Etna, and other non-arid areas, MERIS cannot be used to correct the PWV effects on a regular basis because cloud covers the surface for much of the time.

The output of the Etna-UM model is written to file every half hour. By default we use the output results closest to the radar acquisitions (i.e. 0900 UTC for the descending pass and 2100 UTC for the ascending pass). However, the accurate representation of any lateral atmospheric gradients in the nested mesoscale model, particularly water vapour, is dependent on the initial conditions of the global model (Webley et al., 2004). Rapidly moving frontal systems, only crudely represented at the global analysis scale, are the main problem in this regard. Zhu et al. (2007) showed how high acquisition frequency water vapour imagery from the Meteosat satellite can sometimes be used to track upper tropospheric troughs, to provide an independent measure of any timing bias in the model representation of water vapour. However, poor representation of more subtle gradients in water vapour in the initial conditions may lead to undetected errors in the timing of the nested model results.

Our implementation of the mesoscale UM can compute the phase transitions from vapour to liquid water to ice. The 3D cloud water fields have been modelled and their radar delay fields calculated for two example cases, one in summer and one winter (Fig.6). For the case of 0900 UTC 22 June 2005, precipitable liquid water (PLW) values were typically less than $0.3 \mathrm{~mm}$ over most of Sicily, with a few clouds in the southeast reaching up to 3 $\mathrm{mm}$ (not shown). The model indicated no precipitable solid water (PSW) was present at this time. Over Etna, this resulted in LOS delay values on the southern flanks that were less than $1 \mathrm{~mm}$ (Fig.6b). This compares to a range of PWV values of about $20 \mathrm{~mm}$ over the volcano, resulting in phase delay variations of up to $140 \mathrm{~mm}$ (Fig. 6a). For the colder 2 February 2005 case, the model predicted PSW levels in the mountains north of Etna and over the Ionian Sea to the east of over $3 \mathrm{~mm}$ (not shown). Over most of Etna much lower levels $(<0.6 \mathrm{~mm})$ were modelled. The contemporary PLW field was almost uniform at very low levels $(<0.1 \mathrm{~mm})$. The combined LOS delays are generally uniformly low $(<1 \mathrm{~mm})$, except just to the north of the volcano (Fig.6d). The range in 
delay due to water vapour from the summit to coast is about $100 \mathrm{~mm}$ (Fig.6c). It is clear therefore that in these two cases the influence of suspended liquid and solid water on the overall radar signal delay is between one and two orders of magnitude less than that due to the variable water vapour field. There were no thick cumulo-congestus or cumulonimbus clouds over Etna in these two cases, which would be expected to have a larger, localised effect.

The three-dimensional water vapour, liquid water and ice fields are projected into the radar LOS on a per-pixel basis and the PWV, PLW and PSW contents are calculated. These values are used to calculate the two-way radar LOS delay using the equations of section 4.2 and 4.4. Similarly, the hydrostatic delay is calculated from the surface pressure. Summing these delays gives the total delay map for each radar acquisition time. Differencing the delays of two such appropriate maps and interpolating to a common spatial scale gives the delay difference map for a particular interferogram. Removing this phase map from the interferogram then corrects for the atmospheric component of delay. The resultant corrected interferogram should then reveal any ground motion over the interval of the two radar acquisitions, together with any residual errors from the model and uncompensated long wavelength signals.

One intrinsic problem with this modelling approach merits discussion here. Long wavelength phase ramps in the interferogram can be caused by inadequate measurement accuracy of the satellite's orbital parameters. Orbital positional knowledge, in our case for the Envisat satellite, is insufficiently accurate (a few $\mathrm{mm}$ ) to obviate this. Typically such phase ramps are removed empirically prior to atmospheric correction. Calculation of a best-fit planar gradient to remove the orbital errors relies on the interferogram having sufficient coherence in areas away from deformation fields, where the dominant signal is due to orbital phase gradients only. This criterion may not be satisfied in interferograms over longer intervals, or for cases where coherence is low due to snow or seasonal effects. In these cases, there is a danger that the planar best-fit solution will be biased towards removal of shorter wavelength planar elements of the deformation or water vapour field. It is possible that the planar component of longer wavelength water vapour gradients, for 
example those caused by synoptic fronts, and ionospheric phase gradients may also be removed by such a correction step. Since the water vapour gradients should be modelled by the Etna-UM, they would normally be present in the delay difference map. Thus the same feature may be removed twice, once by the orbital error correction and again by the total delay correction, resulting in a planar over-compensation error in the corrected interferogram. Without some external knowledge to distinguish the planar orbital and atmospheric gradients the simplest way to prevent such over-compensation is to perform a final planar removal step, using a least-squares fit over areas away from expected deformation signals. This has been employed here but is not shown in Fig.5.

\subsection{Magnitude of corrections}

As Beauducel et al. (2000) reported, the range of delay variation due to the atmosphere over Etna is about $150 \mathrm{~mm}$. Interferograms comprising summer (high water vapour) and winter (low water vapour) images can show such a range, whereas same-season pairs usually show a much smaller range of delay. Lacking an absolute independent measurement of delay, it is difficult to estimate the accuracy of the model corrections. Contemporary MERIS radiometer measurements of PWV show agreement with the UM fields equivalent to about $15 \mathrm{~mm}$ rms of delay (Zhu et al., 2007), whilst the assumed-nondeforming-area noise level is about $12 \mathrm{~mm}$ rms (Holley, 2009).

In general the UM models tend to be biased to higher delays relative to other estimates (Holley, 2009). Unsurprisingly, the proportion of correctly assigned delay is greatest for interferograms with a large range of delay and summer-summer interferograms in which the horizontally perturbed component is dominant tend to have the least correctly assigned. One explanation for this is incorrect representation of small scale convective processes in the models. The general non-deformation rms level of noise in the $300 \mathrm{~m}$ resolution data is sometimes worst than that of the $1 \mathrm{~km}$ resolution equivalent. The spatially stochastic nature of developing convective cells at length scales below $10 \mathrm{~km}$ (Zhu et al., 2008) is probably the cause of this. 


\subsection{Correction of an interferogram}

We illustrate the effects of the correction method for a single ascending-pass interferogram created from Envisat ASAR images acquired on 26 May 2004 and 2 November 2005. In this case the intervening eighteen months is sufficient time to allow the accumulation of measurable surface motions. The unwrapped interferogram (Fig.7a), masked for the coherent parts of the volcano, shows an area on the eastern side of the volcano with apparent motion away from the satellite over this period and relative motion towards the satellite on the other sides. But what of the atmospheric effects on these two dates? There were no major frontal features near Etna on either date. The water vapour fields derived from the Etna-UM show similar ranges ( 8-24 mm PWV on 26 May 2004 and $\sim 6-23 \mathrm{~mm}$ PWV on 2 November 2005 from the summit of Etna to sea level). However, the model for 26 May 2004 shows a clear NNE to SSW gradient of increasing PWV across the Ionian Sea to the east of the volcano. The effect of this can just be seen in the "wet" delay field (Fig.7b) derived from the combination of the two model water vapour fields. As previously discussed we remove this planar gradient from Fig.7b (not shown). The main feature in the wet delay difference field is the area of high values (apparent motion towards the satellite) over the upper eastern slopes of the volcano. The atmospheric pressure field on the two dates was very similar and thus the dry delay field (Fig. 7c) is very uniform, contributing little to the correction. Because this is an ascending pass interferogram collected at about 21:46 local time there should be no land-sea breeze effect equivalent to that shown in Fig.3.

Fig.7d shows the interferogram corrected for the wet (with planar gradient removal) and dry difference fields. The motion of the eastern segment of the flank of the volcano away from the satellite is clearly larger than it appeared while obscured by atmospheric signal, whilst the motion on the other flanks has fallen to more neutral values. The displacement across the northern boundary of the moving eastern block co-incident with the Pernicana Fault is obvious. Of course a single interferogram can only measure the component of motion along the line of sight of the radar; in this case about $23^{\circ}$ from vertical towards the 
ENE. Although this is most sensitive to vertical motion, the large signal away from the satellite in the east could also represent a strong easterly component of horizontal motion.

An eruption occurred on Etna between 7 September 2004 and 8 March 2005 that involved effusion of up to 40 million cubic metres of lava from fissures to the southeast of the summit (Neri and Acocella, 2006), mainly during the first half of this period. In the year prior to this eruption, GPS and InSAR data were interpreted by Bonaccorso et al. (2006) to indicate inflation of the western side of volcano and eastward movement of the eastern flank along the curvilinear fault system that trends N-S as it passes through the summit region of the volcano. The quiet, passive draining of lava during the 2004-2005 eruption was interpreted by Neri and Accocella (2006) as the response of a shallow magmatic reservoir to the continued extension across this fault system in late 2004 to early 2005. The eastern flank motion is clearly visible in the corrected interferogram of Fig.7d, and the slight subsidence signal seen around the summit may reflect draining of the shallow reservoir during the first few months of the eruption. This pattern is also seen in the campaign GPS surveys of Bonforte et al (2008, Fig.3a) for the interval July 2004 to July 2005. They show a subsidence pattern at the summit combined with a general southeasterly horizontal motion extending across the eastern flank of the volcano.

\section{Discussion and Conclusions}

Etna is a high relief (conical) volcano whose typical 'bull's-eye' pattern of deformation tends to mimic the topographic modulation of the tropospheric water vapour gradient. Local, topographically-induced flow effects, the proximity of the ocean and the seabreeze effect on water vapour advection are additional problems for InSAR at Etna. Many volcanoes around the world have similar circumstances, particularly the island arc volcanoes in areas such as Indonesia and the Aleutians. These could benefit from an atmospheric modelling approach such as that demonstrated here. 
The sensitivity of the Etna-UM method to the initial conditions in the forecast model is reduced from earlier models (Webley et al., 2004), but still remains a concern. This is particularly the case when there are fast-moving synoptic features such as fronts. Relatively narrow, high gradients of water vapour are likely to be particularly poorly represented in the ECMWF's global initial field, where the model data points are about $60 \mathrm{~km}$ apart. The resultant UM nested model may track the dynamics of the feature but misplace it such that over the $\sim 50 \mathrm{~km}$ domain of Etna, the model time of passage of the feature is offset from observed time (Zhu et al. 2007). Higher spatial resolution of global forecast models (such as the improvement of the ECMWF global analysis models to 16 $\mathrm{km}$ resolution, proposed for 2010) will reduce this problem. Also improved assimilation of water vapour observations, particularly from GPS measurements, into both the initial field and perhaps into the nested model will help in the future.

We conclude from our study that:

Nested mesoscale atmospheric models show promise of being able to provide useful mitigation of the atmospheric path delays experienced by InSAR.

Such models can help calculate the radar path delays due to tropospheric water vapour, the hydrostatic effect and, potentially, those due to rain and ice.

The technique is best suited to regions of high relief, high water vapour variance and specific targets (e.g. island volcanoes in humid zones).

In some conditions the Etna-UM implementation of this method is able to simulate local modifications of water vapour content by mechanisms such as land-sea breezes.

The accuracy of the modelled water vapour fields is similar to that measured by spaceborne radiometers (e.g. MERIS, 1- $2 \mathrm{~mm}$ PWV). The model fields tend to have a positive bias. 
Model results are subject to inaccuracies introduced by too coarse a representation of initial conditions (e.g. the passage of fronts), poor representation of soil moisture and ambiguity with respect to long-wavelength atmospheric gradients caused by poor orbital knowledge.

\section{Acknowledgements}

We are grateful for the suggestions of two anonymous referees who helped improve the paper. This work was supported by NERC grant GR/M86156. The Envisat data were supplied under ESA Cat.1 data grant C1P.2880. RJH acknowledges studentship support from the University of Reading and ESSC.

\section{References}

Askne, J., Nordius, H., 1987. Estimation of tropospheric delay for microwaves from surface weather data. Radio Science, 22, 379-386.

Beauducel, F., Briole, P., Froger, J-L., 2000. Volcano-wide fringes in ERS synthetic aperture radar interferograms of Etna (1992-1998): deformation or tropospheric effect? Journal of Geophysical Research, 105, 16391-16402.

Berardino, P., Fornaro, G., Lanari, R., Sansosti, E., 2002. A new algorithm for surface deformation monitoring based on small baseline differential SAR interferograms. IEEE Transactions in Geoscience and Remote Sensing, 38, 2202-2212.

Bonaccorso, A., Bonforte, A., Guglielmino, F., Palano, M., Puglisi, G., 2006. Composite ground deformation pattern forerunning the 2004-2005 Mount Etna eruption. Journal of Geophysical Research, 111, B12207.

Bonforte, A., Bonaccorso, A., Guglielmino, F., Palano, M., Puglisi, G., 2008. Feeding system and magma storage beneath Mt. Etna as revealed by recent inflation/deflation cycles. Journal of Geophysical Research, 113, B05406.

Davis, J.L., Herring, T.A., Shapiro, I.I., Rogers, A.E.E., Elgered, G., 1985. Geodesy by 
radio interferometry: effects of atmospheric modelling errors on estimates of baseline length. Radio Science, 20, 1593-1607.

Davis, T., Cullen, M.J.P., Malcolm, A.J., Mawson, M.H., Staniforth, A., White, A.A., Wood, N., 2005. A new dynamical core for the Met Office's global and regional modelling of the atmosphere. Quarterly Journal of the Royal Meteorological Society, 131(B), 1759-1782.

Delacourt, C., Briole, P., Achache, J, 1998. Tropospheric corrections of SAR interferograms with strong topography: application to Etna. Geophysical Research Letters, 25, 2849-2852.

Ding, X-1., Li, Z-w., Zhu, J-j., Feng, G-c., Long, J-p. 2008. Atmospheric effects on InSAR measurements and their mitigation. Sensors, 8, 5426-5448.

Elgered, G., Davis, J.L., Herring, T.A., Shapiro, I.I., 1991. Geodesy by radio interferometry: water vapor radiometry for estimation of the wet delay. Journal of Geophysical Research, 96, 6541-6555.

Emardson, T.R., Derks, H.L.P., 2000. On the relation between the wet delay and the integrated precipitable water vapour in the European atmosphere. Meteorological Applications, 7, 61-68.

Favalli, M., Mazzarini, F., Pareschi, M.T., Boschi, E., 2004. Role of local wind circulation in plume monitoring at Mt. Etna volcano (Sicily): insights from a mesoscale numerical model. Geophysical Research Letters, 31, L09105, doi:10.1029/2003GL019281.

Ferretti, A., Prati, C., Rocca, F., 2001. Permanenent scatterers in SAR interferometry. IEEE Transactions Geoscience and Remote Sensing, 39, 8-20.

Foster, J., Bevis, M., 2003. Lognormal distribution of precipitable water in Hawaii, Geochemistry, Geophysics, Geosystems, 4/7, 1065, doi:10.1029/2002GC000478.

Foster, J., Brooks, B., Cherbubini, Sharat, C., Businger, S., Werner, C.L., 2006. Mitigating the atmospheric noise for InSAR using a high resolution weather model. Geophysical Research Letters, 33, L106304,doi:10.1029/2006GL026781.

Goldstein, R. 1995. Atmospheric limitations to repeat-track radar interferometry. Geophysical Research Letters, 22, 2517-2520. 
Hanssen, R.F., 2001. Radar interferometry: data interpretation and error analysis. Kluwer Academic, Dordrecht, The Netherlands.

Holley, R., 2009. Mitigating atmospheric path delays in radar interferometry over volcanoes - atmospheric modelling and persistent scatterer techniques. University of Reading, $\mathrm{PhD}$ thesis.

Holley, R., Zhu, M., Wadge, G., 2005. InSAR measurement of volcanic deformation at Etna - interferogram atmospheric correction methods and the role of forward atmospheric modelling. Proceedings Remote Sensing and Photogrammetric Society Conference, Portsmouth, September 2005.

Li, Z., Muller, J-P., Cross, P., Fielding, E.J., 2005. Interferometric synthetic aperture radar (InSAR) atmospheric correction: GPS, Moderate Resolution Imaging Spectrometer (MODIS) and InSAR integration. Journal of Geophysical Research, 110, B03410, doi:10.1029/2004JB003446.

Li, Z., Fielding, E.J., Cross, P., Muller, J-P., 2006. InSAR atmospheric correction: GPS topography-dependent turbulence model (GTTM). Journal of Geophysical Research, 111, B02404, doi:10.1029/2005JB00371.

Massonnet, D., Feigl, K.L., 1998. Radar interferometry and its application to changes in the earth's surface. Reviews of Geophysics, 36, 441-500.

Mattar, K.E., Gray, A.L., 2002. Reducing ionospheric electron density errors in satellite radar interferometry applications. Canadian Journal of Remote Sensing, 28, 593600 .

Met Office, 2004. Unified Model User Guide, http://www.cgam.nerc.ac.uk/um/docs, http://ncas-cms.nerc.ac.uk/component/option,com_docman/task,cat_view/gid,38/.

Neri, M., Acocella, V., 2006. The 2004-2005 Etna eruption: implications for flank deformation and structural behaviour of the volcano. Journal of Volcanology and Geothermal Research, 158, 195-206.

Puyssegur, B., Michel, R., Avouac, J-P., 2007. Tropospheric phase delay in interferometric synthetic aperture radar estimated from meteorological model and multispectral imagery. Journal of Geophysical Research, 112, B05419, doi:10.1029/2006JB004352. 
Rosen, P.A., Hensley, S., Joughin, I.R. et al., 2000. Synthetic aperture radar interferometry. Proceedings IEEE, 88, 333-382.

Sandwell, D.T. , Price, E.J., 1998. Phase gradient approach to stacking interferograms. Journal of Geophysical Research, 103, 30183-30204.

Solheim, F.S., Vivekanandam, J., Ware, R.H., Rocken, C., 1999. Propagation delays induced in GPS signals by dry-air, water vapor, hydrometeors and other particulates. Journal of Geophysical Research, 104, 9663-9670.

Tarayre, H., Massonnet, D., 1996. Atmospheric propagation heterogeneities revealed by ERS-1 interferometry. Geophysical Research Letters, 23, 989-992.

Wadge, G., Webley, P.W., James, I.N., Bingley, R., Dodson, A., Waugh, S., Veneboer, T., Puglisi, G., Mattia, M., Baker, D., Edwards, S.C., Edwards, S.J., Clarke, P.J., 2002. Atmospheric models, GPS and InSAR measurements of the tropospheric water vapour field over Mount Etna. Geophysical Research Letters 29/19, 2002 GL015159.

Wadge, G., Zhu, M., Holley, R.J., 2006. Forward atmospheric modelling to correct for water vapour delays to InSAR ground deformation measurements over mountains. Geophysical Research Abstracts, 8, 0734.

Webley, P.W., Wadge, G., James, I.N., 2004. Determining radio wave delay by nonhydrostatic atmospheric modelling of water vapour over mountains. Physics and Chemistry of the Earth, doi:10.1016/j.pce2004.01.013.

Williams, S., Bock, Y., Fang, P., 1998. Integrated satellite interferometry: tropospheric noise, GPS estimates and implications for interferometric synthetic aperture radar products. Journal of Geophysical Research, 103, 27051-27067.

Zhu, M., Wadge, G., Holley, R.J., James, I.N., Clark, P.A., Wang, C., Woodage, M.J., 2007. High-resolution forecast models of water vapor over mountains: comparison with MERIS and Meteosat data. IEEE Geoscience and Remote Sensing Letters, 4/3, 401-405.

Zhu, M., Wadge, G., Holley, R.J., James, I.N., Clark, P.A., Wang, C., Woodage, M.J., 2008. Structure of the precipitable water vapour field over Mount Etna. Tellus-A 60A, 679-687.. 


\section{Figure Captions}

Fig.1 Nested domains for the Etna-UM model. The three white rectangles show the approximate outer boundaries of the 12,4 and $1 \mathrm{~km}$ domains. The $0.3 \mathrm{~km}$ domain over Mount Etna is not shown.

Fig.2 Shaded relief image of east Sicily showing the area (white box) of the $0.3 \mathrm{~km}$ resolution domain of the Etna-UM. The black boxes show the approximate areas covered by the ASAR radar images typically acquired on the descending (D) and ascending (A passes of the ENVISAT satellite.

Fig.3 Two components of the water vapour field over Etna at 1027 UTC 27 July 2005. a and $b$ are the mean horizontal precipitable water vapour fields (in $\mathrm{mm}$ ) observed by the spaceborne MODIS radiometer and simulated by the Etna-UM forward model respectively. $\mathrm{c}$ and $\mathrm{d}$ are the equivalent horizontally perturbed components respectively (after Zhu et al., 2008).

Fig.4 Variation of the value of Q with elevation of the surface of Etna for a variety of cases. The solid and dashed lines are for ascending and descending passes respectively. The red curves are summer cases (June-August), yellow are autumn cases (SeptemberNovember), blue are winter (December-February) and green are spring cases (MarchMay). The $Q=6.3$ value of Webley et al. (2004) is shown by the vertical black line.

Fig.5 Flow schematic of the Etna-UM method for interferogram correction.

Fig.6 The modelled (1 km resolution) LOS delay (in $\mathrm{mm}$ ) over Etna due to (a) water vapour (wet delay) and (b) liquid water at 0900 UTC 22 June 2005. Panel (c) shows the water vapour delay field, and (d) the combined solid and liquid water delay field for 0900 UTC 02 February 2005. Topographic contours are shown every $250 \mathrm{~m}$ of elevation. Note the different scales. 
Fig.7 Correction of the ascending-pass Envisat ASAR interferogram of 26 May 2004 - 2 November 2005 shown superimposed on a shaded relief image of the topography of northeast Sicily: (a) the unwrapped interferogram in $\mathrm{mm}$ of apparent relative motion towards the satellite (positive), (b) the Etna-UM modelled difference field for the wet delay, (c) the modelled difference field for the hydrostatic delay, and (d) the resultant interferogram corrected according to: $\mathrm{d}=\mathrm{a}-(\mathrm{b}-$ planar gradient $)-\mathrm{c}$. 


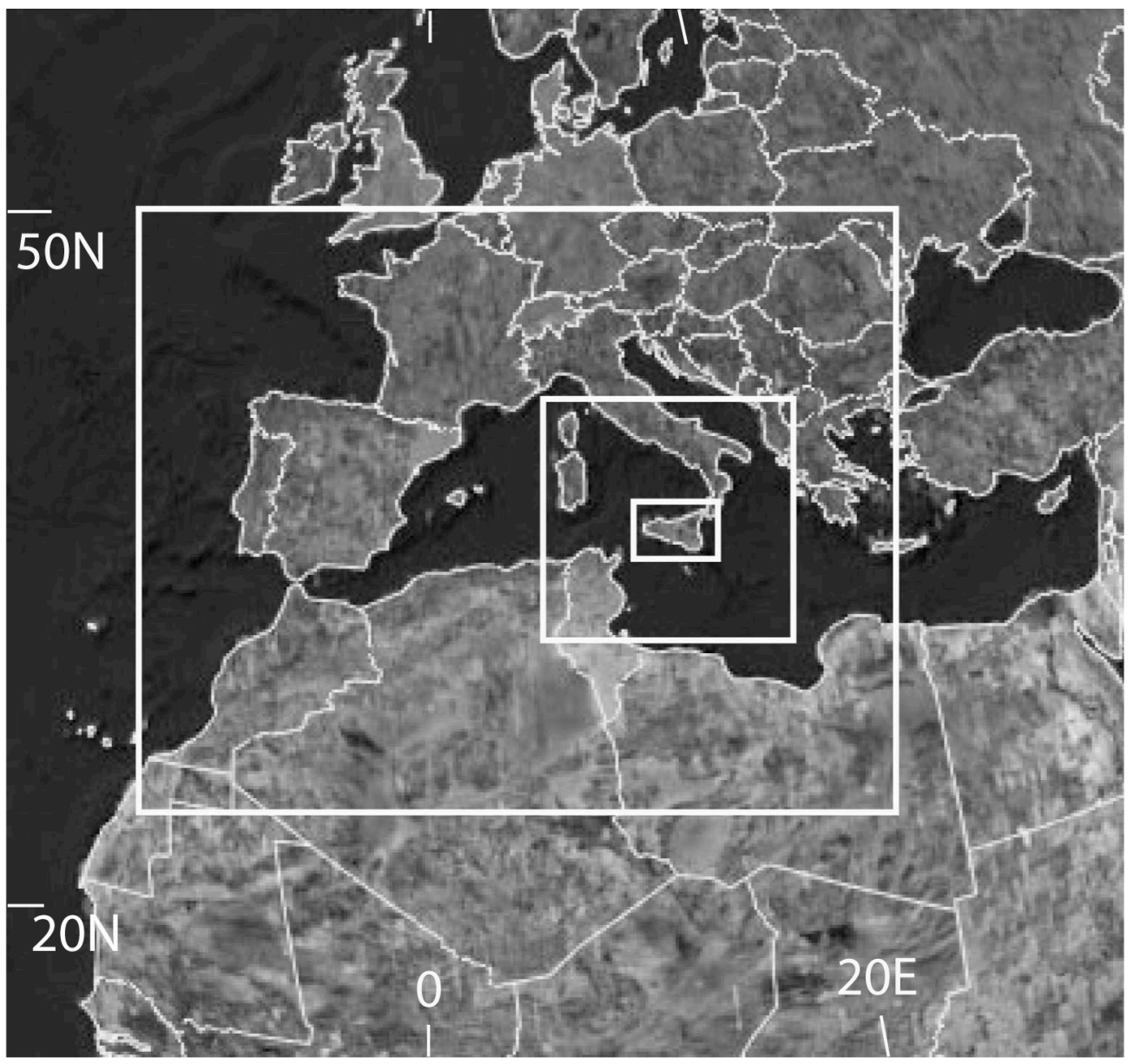

Fig.1 Nested domains for the Etna-UM model. The three white rectangles show the approximate outer boundaries of the 12,4 and $1 \mathrm{~km}$ domains. The $0.3 \mathrm{~km}$ domain over Etna volcano is not shown. 


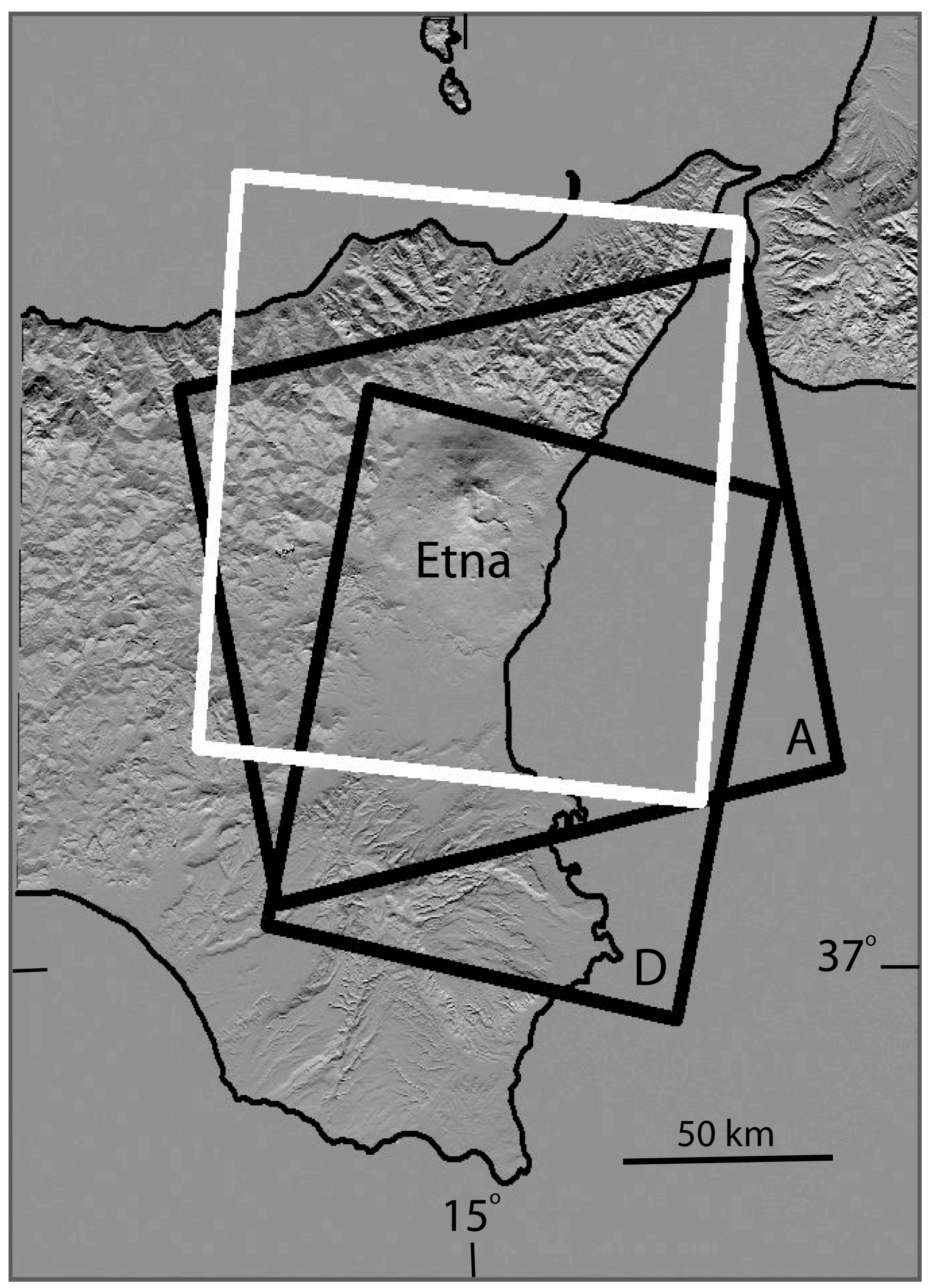

Fig.2 
a

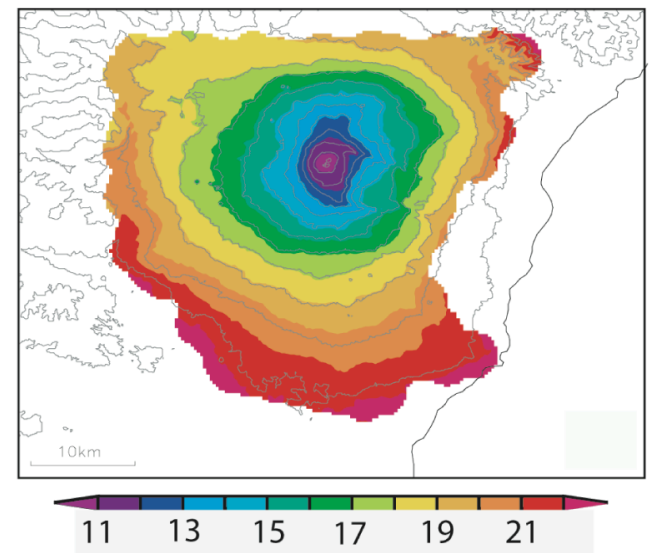

C

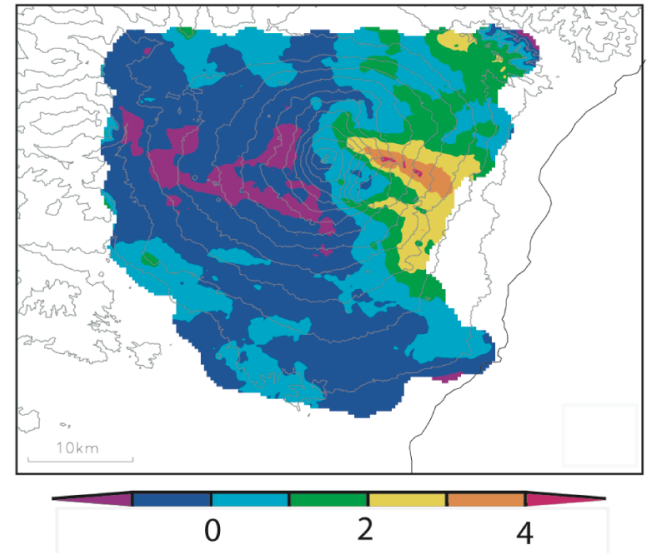

b

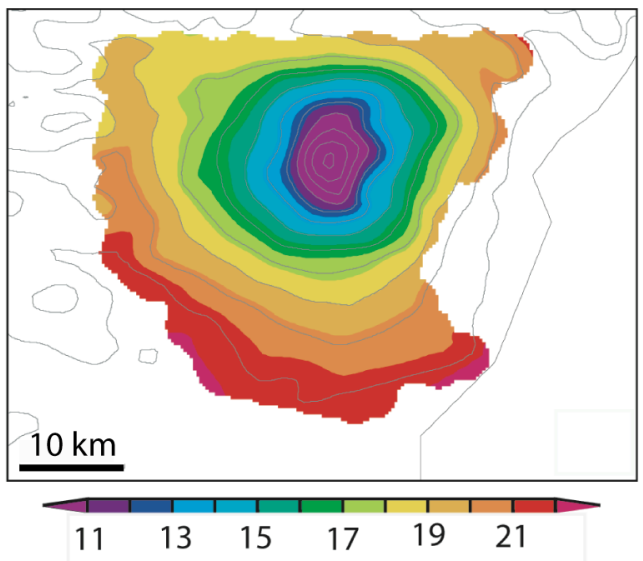

d

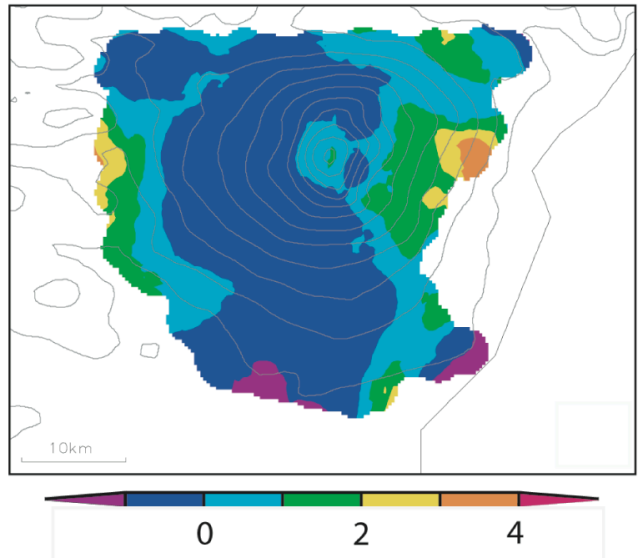

Fig. 3 Two components of the water vapour field over Etna at 1027 UTC 27 July 2005. $\mathrm{a}$ and $\mathrm{b}$ are the mean horizontal precipitable water vapour fields (in $\mathrm{mm}$ ) observed by the spaceborne MODIS radiometer and simulated by the Etna-UM forward model respectively. $\mathrm{c}$ and $\mathrm{d}$ are the equivalent horizontally perturbed components respectively (after Zhu et al., 2008). 


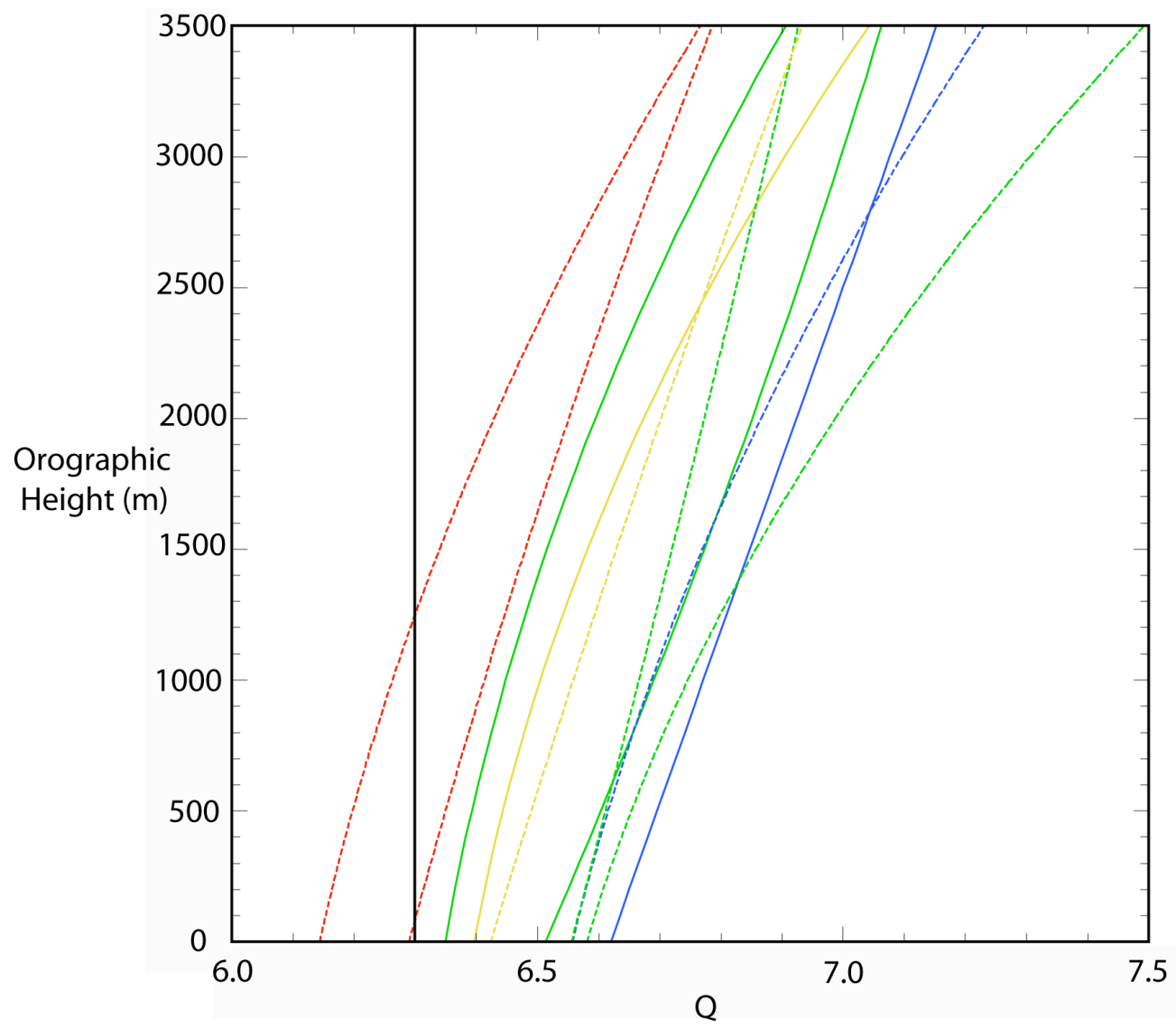

Fig.4 The solid and dashed lines are for ascending and descending passes respectively. The red curves are summer cases (June-August), yellow are autumn cases (September-November), blue are winter (December-February) and green are spring cases (March-May). The $Q=6.3$ value of Webley et al. (2004) is shown by the vertical black line. 


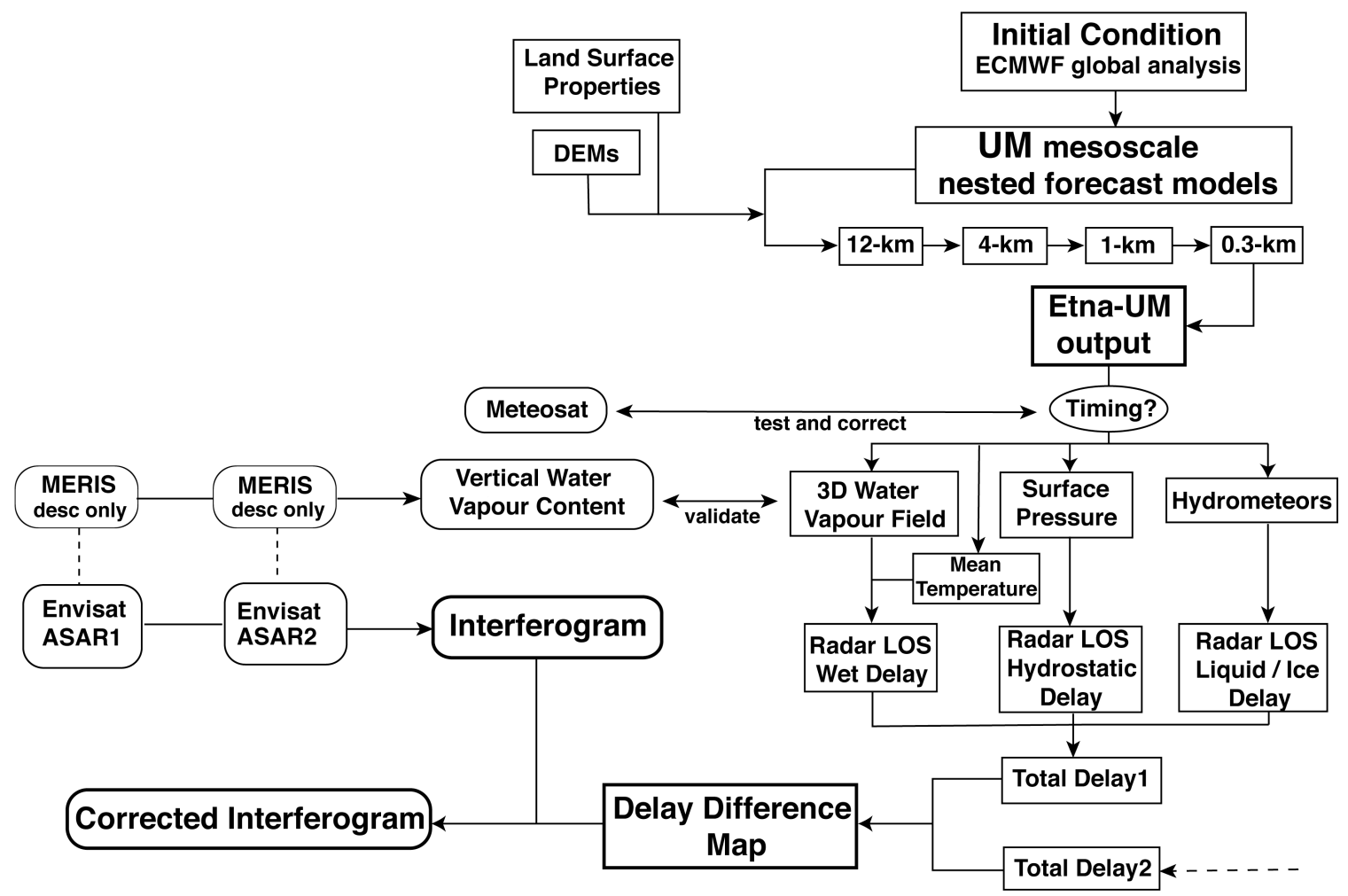

Fig.5 Flow schematic of the Etna-UM method for interferogram correction. 

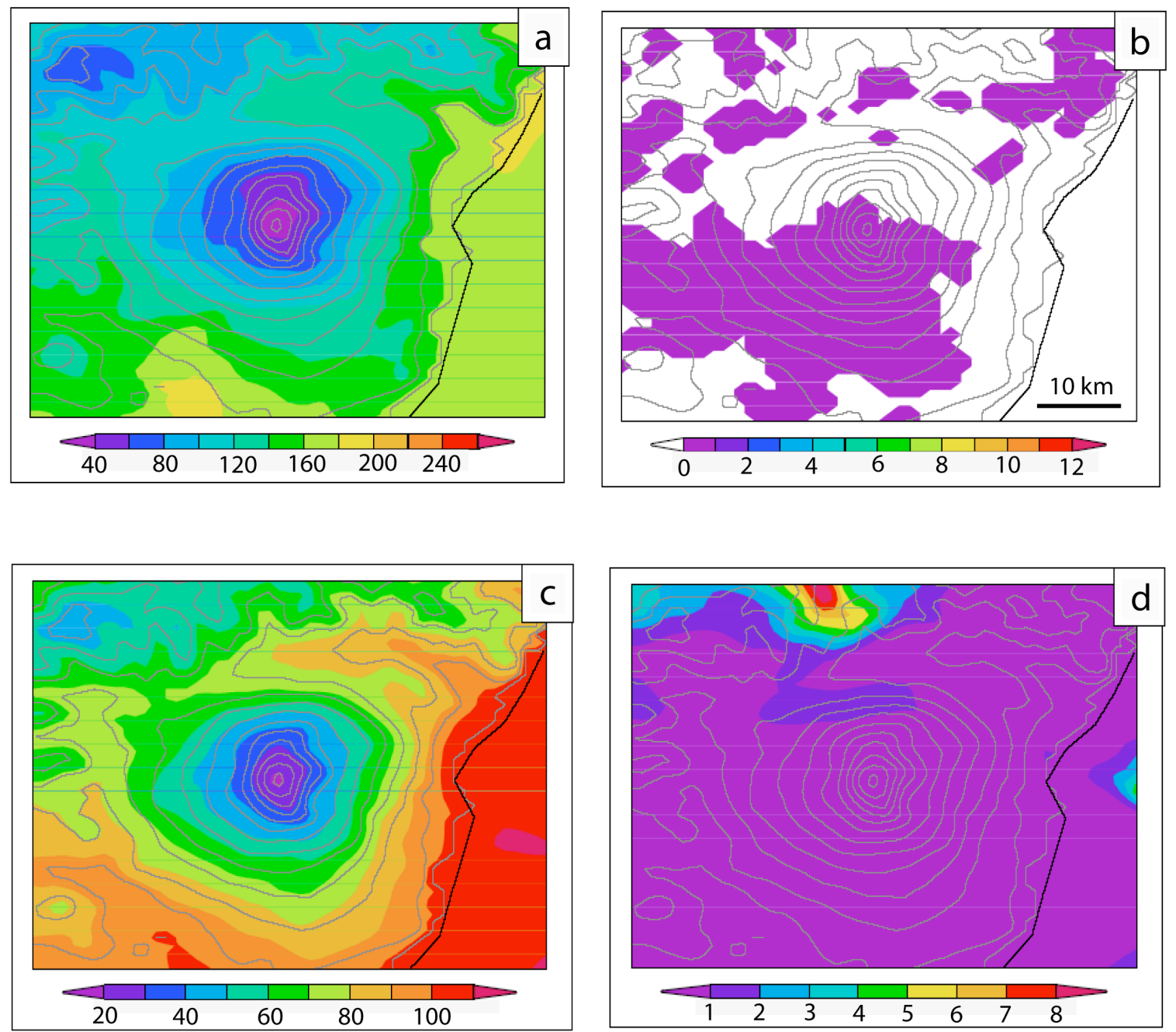

Fig.6 The modelled ( $1 \mathrm{~km}$ resolution) LOS delay (in $\mathrm{mm}$ ) over Etna due to (a) water vapour (wet delay) and (b) liquid water, at 0900 UTC 22 June 2005. Panel (c) shows the water vapour delay field, and (d) the combined solid and liquid water delay field for 0900 UTC 02 February 2005. Topographic contours shown every $250 \mathrm{~m}$ of elevation. Note the different scales. 


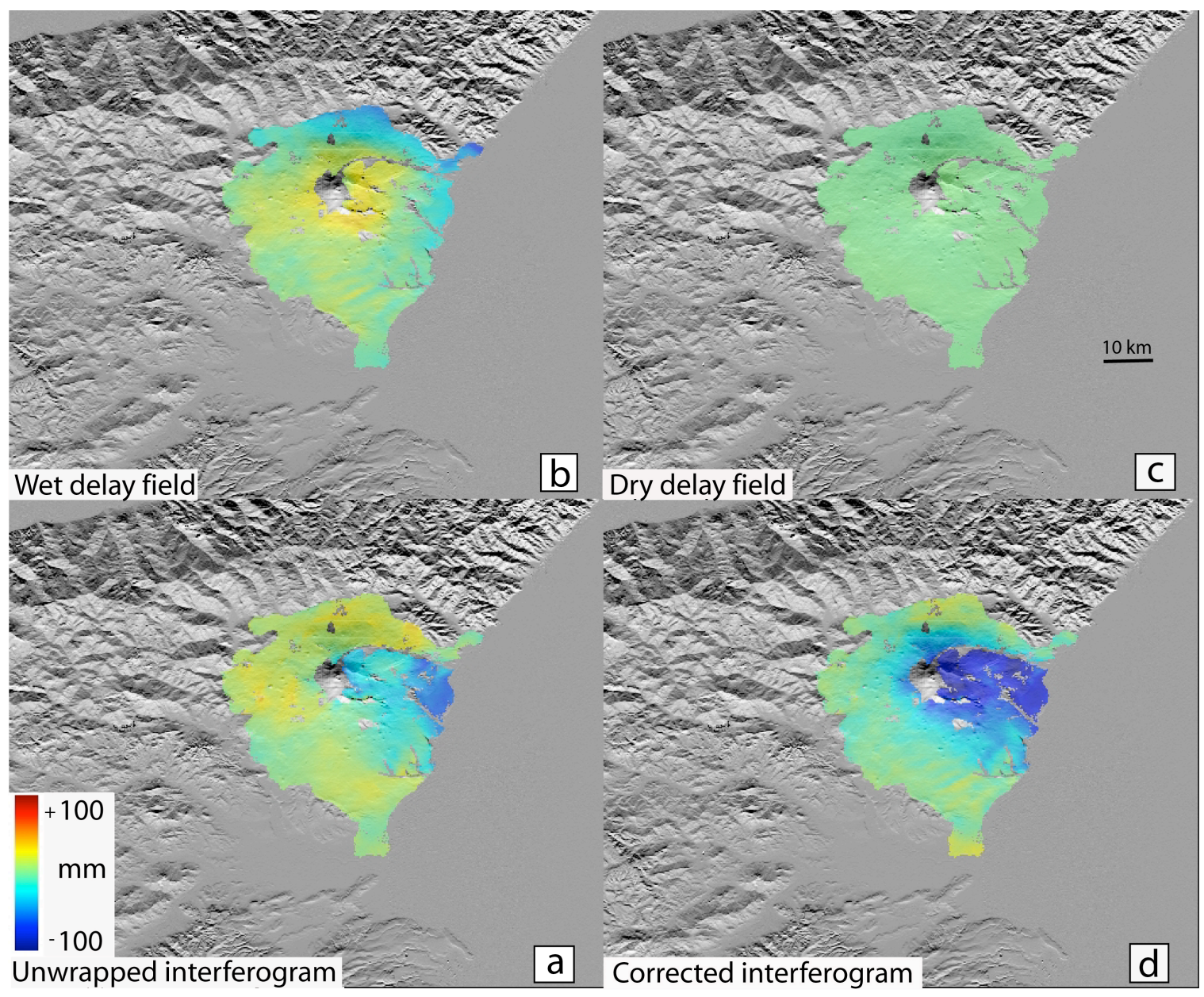

Fig.7 